\title{
Design of a Hexagonal Solar Fish Dryer
}

\author{
N. Lakshminarayanan, R. Mahesh, R. Amalraj, Mithun. N. P, Jayakumar Nair
}

\begin{abstract}
Solar drying is a general methodology adopted to protect agricultural goods, fishes as well as meat in tropical as well as subtropical areas. Drying helps to maintain the quality of product and improve its shelf-life by bringing down the wastage to minimum levels. Conventional driers have lot of limitations like infestation by insect, rodents, other animals, exposure to wind-borne dirt and dust, lack of proper monitoring as well as escalated cost of the automatic dryers. Solar dryers are being used all around the world in different countries in varied models. These dryers are of two different methods one that work with natural convection with air-flow established by buoyancy and the other with air flow by a fan in forced convection mode. This is a paper on the outcome of a solar dryer designed especially for fisherman to dry fishes effectively. A different configuration with an objective to capture major amount of incident solar energy and dry fishes at a faster rate is being suggested as an alternative.
\end{abstract}

Keywords: Fish drying; hexagonal configuration; Solar Drier.

\section{INTRODUCTION}

Drying is a usual technique applied for preserving provisions products for longer periods maintaining its nutrition quality as well as strength? The heat from the sun with the wind has been used to dry food harvest since years. Thermal Energy derived from solar radiation is the cheapest form, for use in drying process. Solar air heaters are very simple to design, manufacture and assemble hence preferred over other methods, involving fossil fuel or electricity. This dryer is working in a lot of applications that need small to reasonable heat below $75^{\circ} \mathrm{C}$.

Fishes are being dried since ages in open beaches and far late in electric driers for ease of production in increased quantities. High prices, rising pollution, shortage of fossil fuels have increased the emphasis on using alternative renewable energy resources. Drying of fish using renewable solar energy is absolutely environmental friendly with almost zero impact. Fishes are an extremely perishable foodstuff that can get spoiled easily by the consequence of the action of

Revised Manuscript Received on December 30, 2019.

* Correspondence Author

N.Lakshminarayanan *, Associate Professor, Mechanical Engg., Aarupadai Veedu Institute of Technology Vinayaka Missions Research Foundation, Chennai. India

R.Mahesh, Assistant Professor Grade II, Mechanical Department, Aarupadai Veedu Institute Of Technology, Vinayaka Mission's Research Foundation, Chennai. India.

R. Amalraj, UG Student, Dept. of Mechanical Engg, Aarupadai Veedu Institute of Technology, Vinayaka Missions Research Foundation, Chennai. India.

Mithun.N.P, UG Student, Dept. of Mechanical Engg, Aarupadai Veedu Institute of Technology, Vinayaka Missions Research Foundation, Chennai. India.

Jayakumar Nair, UG Student, Dept. of Mechanical Engg, Aarupadai Veedu Institute of Technology, Vinayaka Missions Research Foundation, Chennai. India.

(C) The Authors. Published by Blue Eyes Intelligence Engineering and Sciences Publication (BEIESP). This is an open access article under the CC BY-NC-ND license (http://creativecommons.org/licenses/by-nc-nd/4.0/) bacteria and enzymes available in the fish, and causes rancidity due to the chemical oxidation of the fat. At high

temperatures common in tropical countries, both enzymes action and bacterial action is improved. To minimize the autolytic and micro bacterial activity the captured fishes are processed or preserved in various ways unless within few hours of capture the fish become spoiled.

Fish drying is being carried out by spreading them on the on beaches, on rocks or on ground, to dry in the sun. To avoid contamination of the fish by sand, dirt and mud, the mats and reeds are laid on the ground.

Recently a sloped drying rack has been introduced as a simple but often effective improvement.

Salting and drying are traditional methods of preserving fish. Dried salted products are still popular in many areas among the world as an edible food. During drying of fresh fish the moisture content is minimized around 25\%, autolytic activity is minimized and bacteria cannot survive. However the to avoid the growth of mold, the content of moisture should be minimized to $15 \%$.The occurrence of salt slowdowns the action of bacteria and by osmosis the water content removed. Before drying the fish when the salt is added the content of moisture in the flesh is $35-45 \%$,on the basis of the salt concentration it may be adequately low to reduce the bacteria.Rack drying process often applied for obtaining a cleaner fish as exposure to dirt is reduced and accessibility to domestic animals and pests, such as mice, rats and crawling insects, which contaminate or consume them is also brought down drastically. Waterproof enclosures are used for protecting from rain. Drying rates are increased by arranging trays at a meter above the ground as air currents are stronger above the ground. The use of a sloping rack allows any exudates to drain away. An alternative approach to the configuration of solar dryer is designed and its feasibility is analyzed in this paper. Many form of solar dryer for use with agricultural and fisheries products have been developed in many parts of the world; Various structures of solar dryers are developed for fisheries and agriculture products [1]. Only some of these are used particularly with fish, and no direct comparative exercise is reported on the relative performance of any of the types available.

\section{LITERATURE REVIEW}

Sun is regarded most important renewable sources of energy. It includes both light energy as well as thermal energy. Hence solar energy can be simply referred as the assemblage of the radiant light and heat from the sun. The thermal system seeks to store the heat from the sun that can be converted and can be used for a wide variety of applications such as solar heaters etc., whereas the light from the sun can be employed for applications such as photo-voltaic cells. 
Thermal energy from the sun has enormous applications in vast areas and it has a significant role in the field of drying. Simply drying can be defined as the process by which any object is exposed to the process of dehydration. If this drying process takes place by the use of sunlight, it is called as solar drying and the devices that promote the drying process in the presence of sun are called as solar dryers. Generally the process of Sun drying is the earliest method of drying farm produce ever known to man. Generally, the solar dryers are classified into many types based on different criteria. These mainly include:

- Air movement

- Availability of sunlight

- Characteristics feature of the product to be dried.

- Orientation of the components of dryer

- Type of supplies used in the structure of the dryer

- Mode and direction of the wind

\section{A. Classification}

The solar dryers are able to largely classify under two heads based on process of collection as well as conversion of solar power into useful power through the products subjected to drying and also based on the above criteria [2]. These include:

1. Direct solar dryers

2. Indirect solar dryers

\section{A. Direct Solar Dryers}

In direct solar dryers, the substances are exposed to dehydration to the straight received solar emission. These include the drying of the food and clothes. In this method, the products to be dried are spread on the mats, or ground or cement floor. The solar energy coming from the sun strikes these products. A part of this incoming energy is absorbed and the rest of the power be reflect back into the impression. The power absorbed by these products gets changed into useful thermal power as well as as a consequence, the temperature of the goods starts to augment. The wavelength absorbed by the crops or other products depends upon its color. This method is the cheapest and simple drying method ever adopted. However, as per evaluation on circumlocutory Solar Dryers, which was published by ARPN Journal of Engineering and Applied Sciences, though this is an easy as well as cheap method, direct solar drying possesses is shown Fig. 1, and the following disadvantages:

- Non uniform drying.

- Large time consumption.

- Chance of reduction of excellence of goods in conditions of the vitamins as well as nutrients present in them.

- Failure to establish control over the rate of drying.

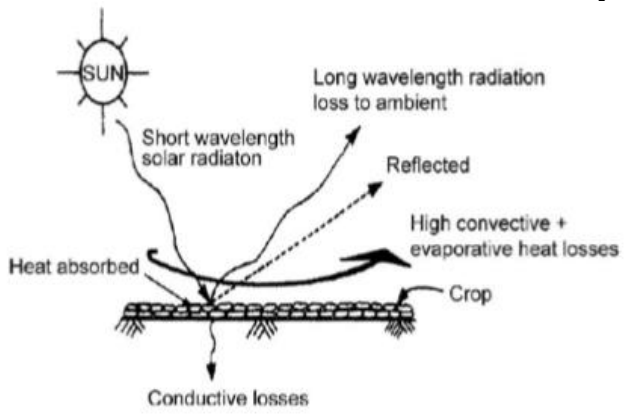

Fig. 1.Direct Solar Drying

\section{B. Indirect Solar Dryers}

In circumlocutory solar dryers, the solar temperature energy coming from the sun is absorbed by a black surface which results in the heating up of the air and this air is transferred to the substances which are to be dried.

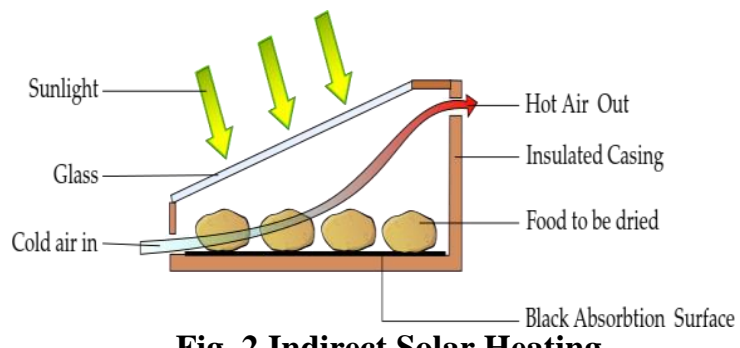

Fig. 2.Indirect Solar Heating

In the case of circumlocutory solar dryers, the the majority valuable feature be that the food or any other substances which are subjected to drying can be protected from undergoing contamination weather wind blowing or by birds, insects or animals. And also suitable control can be established on the rate of drying of the products by maintaining a suitable temperature by means of suitable devices. Indirect solar drying in Fig. 2 can be invariably used with minimum time requirement for the drying process and it can minimize the disadvantage of direct solar dryers to a great extent. However as a result of the developing science and technology, many remarkable researches has taken regarding the development of the idea of solar dryers, though the primary aim is to dry the goods with great efficiency. As a result, further investigations were carried out during the learning of the circumlocutory solar dryers and many improvements in the indirect solar dryers. These were further classified as follows,

- Indirect Type Natural Convection Solar Dryers

- Indirect Type Forced Convection Solar Dryers

\section{A. Indirect Type Natural Convection Solar Dryers}

Circumlocutory normal convection dryer has a remarkable responsibility in the solar drying process. A significant example of the indirect type natural convection solar dryer was developed by A. Madhlopa developed an indirect type natural convection solar dryer which is a total integration of a solar dryer along with collector- storage and biomass-backup heaters).This dryer consists of a rectangular duct and a flue gas chimney, in which a biomass burner was installed.

The experimental procedure regarding the development of this dryer was done in three modes namely: solar mode, biomass mode and solar-biomass mode. The storage material used in this dryer was pineapple which was consecutively done in twelve pineapples with a batch weight of $20 \mathrm{~kg}$.

The conclusion drawn from the analysis of the experimental procedure was that the storage materials with in the dryer utilized the energy from the absorbed solar energy as well as the heat from the burner. However this method effectively produced results during the time of peak sunshine hours. There was a different behavior of the solar dryer when it is operated on solar-biomass mode. The system possessed a positive response even during unfavorable climatic conditions. This gained a remarkable decrease in the moisture content of the pineapple. 


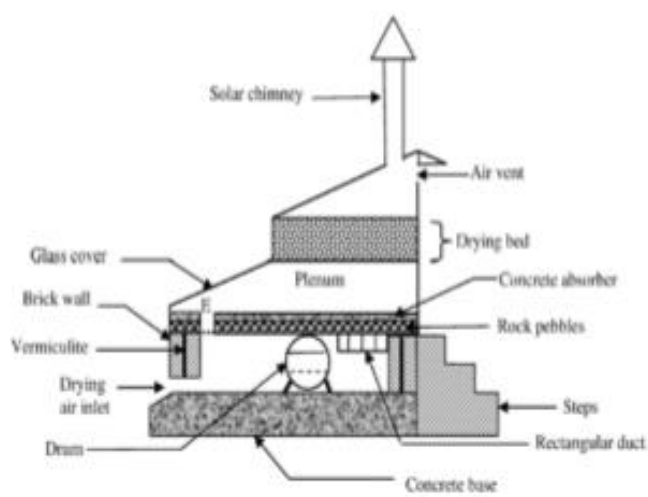

Fig. 3.Indirect Type Natural Convection Solar Dryers

Subarna Maiti has put forwarded a new system circumlocutory category normal convection solar dryers is represent in Fig. 3 which has included a north - south reflectors. These reflectors have an extraordinary power concerning the absorption of the solar radiation than that available by means of usual conventional solar dryers. This ultimately lead to the increase of the overall efficiency of the solar and enhanced the results by an increment of about $40 \%$. They adopted a storage material called "papad" which is an Indian wafer with significant drying property. The entire moisture content present within papad was vaporized within a minimum duration of 5 hours by spreading the wafer to an area of about $1.8 \mathrm{~m} 2$. The major challenge possessed by the inventors of this dryer is that certain food material after drying was followed by intolerable hardness. This was due to the occurrence of excessive drying, because no provisions were made in this system to control the effective temperature within the dryer. Fig. 4 shows that the processing of circumlocutory type normal convection solar dryers

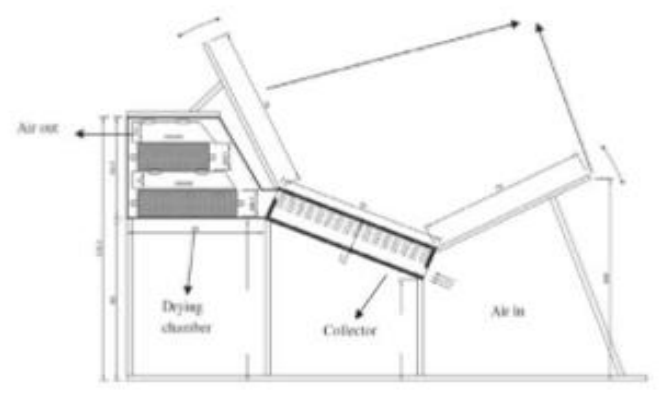

Fig. 4.Processing of indirect type natural convection solar dryers

J. E. Berinyuy had made an intensive study regarding the circumlocutory category normal solar dryers. The model was accompanied by its construction by the integration of a twice pass solar tunnel dryer with heat storage. The heat storage was achieved by the usage of locally available materials. He used this representation for the ventilation of many undeveloped goods and leafy vegetables. The dryer was kept at an inclination of about $6^{\circ}$ so that there is an effective incidence of solar energy and its value was calculated to be about $12.03 \mathrm{KJ} / \mathrm{m} 2$ per day. The heat storage within this dryer has also maintained a temperature of about $5^{\circ} \mathrm{C}$ during the off sunshine hours. By examining the results, it was experimental that the dryer has condensed the wetness satisfied of $17 \mathrm{~kg}$ of cabbage to $95 \%$ in length of regarding five days.

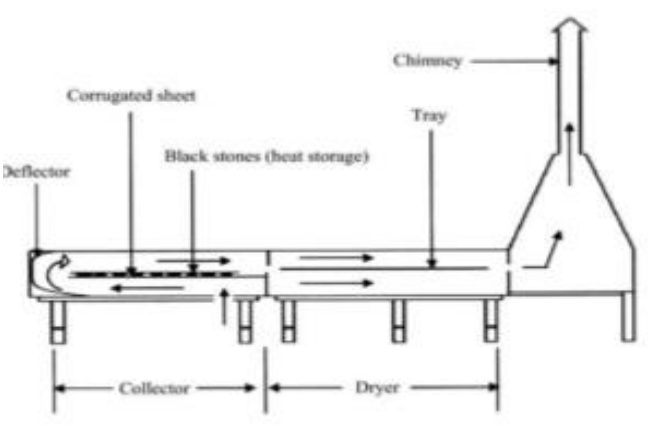

Fig. 5.Flat Plate Indirect Natural Convection Solar Dryers

A.A. El-Sebaii has designed an indirect type natural convection solar dryer consisting of flat plate that acts a solar air heater which is in turn connected to a cabinet, is shown in Fig 6. This cabinet acts as the drying chamber. The involvement of the air heater within this system made it possible to insert any kind of material for the process of dehydration. Apart from all other dryers, in this model, sand is used as the storage material. They also conducted many experiments with and without storage materials. The model possessed a fine behavior even for the drying of the fruits including seedless grapes. The storage material had shown a significant reduction in the drying process by 60-72 hours. For achieving better results, the fruits were dried only after it is cut into small piece which was chemically treated by simply dipping these materials in hot water. The main conclusion drawn by this experiment was that about $10 \mathrm{~kg}$ of grapes were dried with in duration of 20 hours of sunshine after these grapes were treated chemically.

\section{B. Indirect Type Forced Convection Solar Dryers}

Apart from the direct type natural convection dryer, the indirect dryer also include indirect type forced convection dryer is shown in Fig. 7. In this for the usual PCM material, a phase change of material was made and a new dryer was developed by R. Velraj. This phase change was developed by heating the storage material in the absence of air. Instead of PCM, they made the full advantage of HS 58, which is an inorganic salt which has a capacity to store the heat energy available from the sun during the sunshine hours and they effectively uses this sunlight for the drying process during off sunshine hours. This resulted in the reduction of heat losses, which made the system more efficient compared to the earlier existing solar dryers, this was effectively during the high mass flow rates. Also they further preceded their study by means of using different varieties of phase materials under different temperatures based on the characteristic properties of the phase material. They examined that there was a reduction in the overheating of the system during the peak sunshine hours. This prevention of the system from overheating resulted in the preservation of the quality of the food during the whole drying period. Also this resulted in the uniform distribution of heat throughout the dryer. Processing of indirect type force convection solar dryers is represent in Fig.8. 


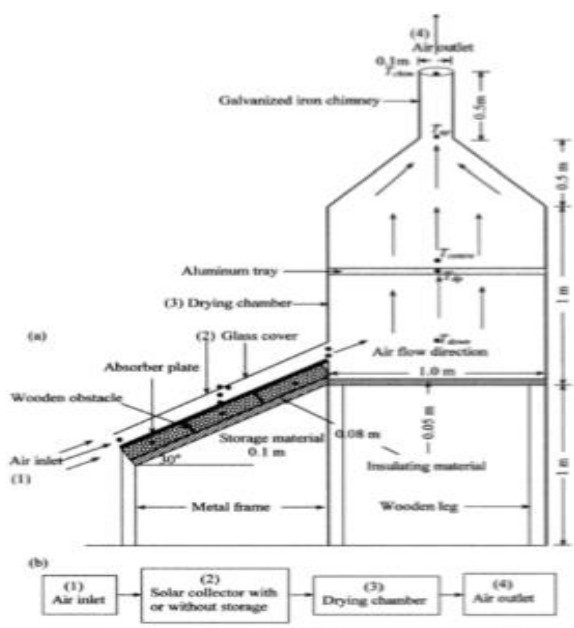

Fig. 6.Indirect Type Forced Convection Solar Dryers

In Another innovation made regarding the dryer was a cabinet type dryer that was developed by Bukola O. Bolaji in Nigeria. The average wind velocity of the system was regarded as $1.62 \mathrm{~m} / \mathrm{s}$ and an average deficiency of the dryer system was about $46.7 \%$. This was mainly concerned with the drying of the yarn chips and pepper. The temperature maintenance of the system was made in such a technique that it mechanism efficiently during the day time as well as during the night hours.

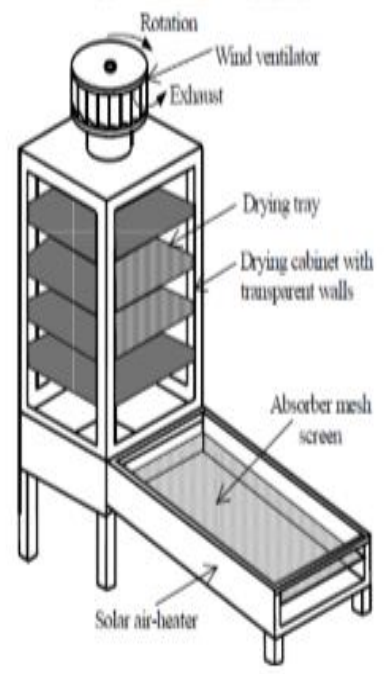

Fig. 7.Processing of indirect type force convection solar dryers

Circumlocutory type compulsory convection solar dryer was developed through many personalities as well as among them, the design developed by M. Mohanraj as well as P. Chandrasekar [3] gained great popularity. They designed this solar dryer for drying chillies in which the process of convection has high importance. It consists of a smooth protect solar atmosphere heater associated to a cabinet which act as the drying assembly room. In this system, provision has made under the absorber plate to insert various storage materials. Because it is placed under the absorber protect, the drying procedure is remarkably augmented. Thermal efficiency of this type $\mathrm{r}$ was predictable to be about $21 \%$ with specific wetness withdrawal rate of about $0.87 \mathrm{~kg} / \mathrm{kW} \mathrm{h}$. Sometimes heat storage materials are enabled with this dryer which is helpful in maintaining an ambient temperature within the dryer.

\section{PROPOSED SYSTEM}

Requirement of low cost for producing larger quantities of high quality dry fish is started in practical action. By mixing the expert and community consultation, a unique solution in the model of a solar powered fish dryer is designed and discussed. The energy cost is zero for using solar energy. The material for this design is sourced easily in local and the design installation cost is simple with moderate. To prevent contamination the dryer is sealed. Compare to the conventional drying methods and other solar drying, this method allows fast drying with very minimal cost.

The hexagonal model is represent in Fig. 9. being suggested in this paper is an outcome of alternative approach for better efficient fish drier for the community. This is a novel approach towards the drying up of fish which has a great enhancement over the conventional fish drying process. The model consists of a regular hexagonal prism in which the phase is inclined at certain angle that ensures the maximum availability of sunlight all over its exposure. Another hexagonal prism consisting of four trays is housed within the glass prism with an air gap spacing of $10 \mathrm{~cm}$ which is distributed uniformly on either sides as well as on the top of the prism. This model is an improved design that offers simplicity in construction, low maintenance cost, enhancement of heating process even during the off sunshine hours, uniform heating of the storage materials, durability, low susceptibility to birds, insects and toward adverse weather conditions.

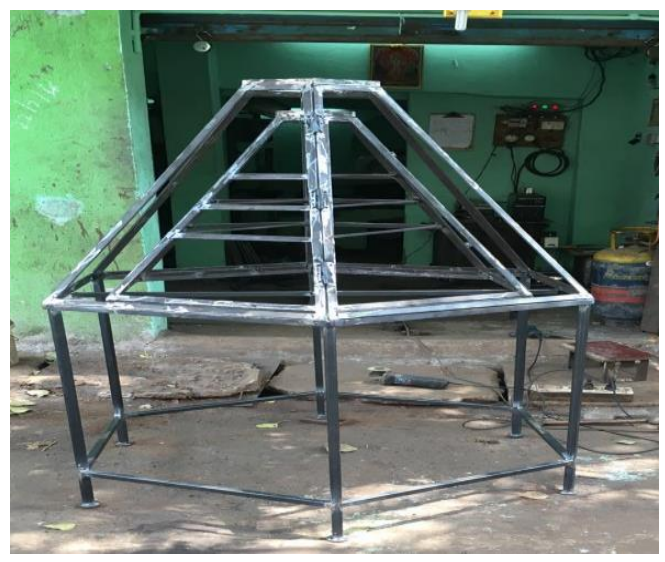

Fig. 8.Hexagonal Frame

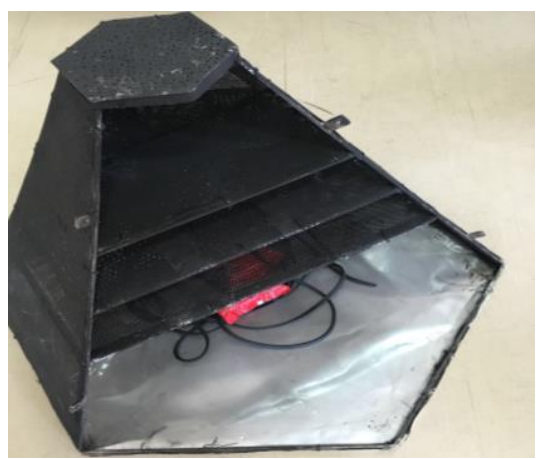

Fig. 9.Fish Tray Thermal Energy Collector

Published By: 
The collector is shown in Fig. 10. and it is a simple model of a inclined solar flat plate type that receives solar radiation and gives hot air to the tune of at least $650 \mathrm{C}$. It is made of mild sreel fabrication with an angle of around 150 for receiving continuous solar radiation and a glazing for protection. The absorber plate is painted black as always to increase the rate of absorption of incident solar radiation.

The hexagonal prism in Fig.9 is provided with glazing as an outside enclosure. Two face of hexagonal prism is designed as doors for placing fish in the tray Fig.10 that is fixed inside the hexagonal frame. The tray after being placed inside the hexagonal frame can be accessible easily through a pair of doors, for easy loading and unloading of fishes.

\section{A. Mild steel}

To construct the skeleton model the mild steel is utilized with less corrosive and strong alloy. In industry this steel is used for the main constructions materials. It provides preliminary selection of best suitable materials for engineering applications with the quick and economical .It has 200GNm2 young modulus. This steel is well known for its high content of carbon ( $0.2 \%$ to $2.1 \%)$, silicon $(0.6 \%)$. copper $(0.6 \%)$, manganese $(1.65 \%)$.This steel is extracted from pig iron with less cost and readily accessible. It is applicable for fabrication like toughness, ductility, high weld ability and machinability. The application for which mild steel was extended generally did not involve the resistance of corrosion as a main consideration; corrosion resistance of alloys and metals is a fundamental property related to the ease with which these metals react with a given environment. With the maximized use of this metal in construction and the manufacturing firms, one of the main harms encountered is the control of corrosion rate when exposed to various corrosive environments.

\section{B. Insulated plate}

Insulator help to reduce the heat transfer between object in thermal contact or in range of radiate influence. The insulating capability is measured with thermal conductivity. Wood is used as an insulator plate as it has good thermal resistance. It act as an insulator because of air pocket present in its cellular structure.

\section{RESULTS AND DISCUSSIONS}

In the procedure of drying, temperature is compulsory to evaporate moisture from the material as well as a flow of air helps in carrying away the evaporated moisture. There are two basic mechanisms involved in the drying process:

1) The movement of wetness from the interior of an entity substance to the surface.

2) The disappearance of wetness from the outside to the nearby space. The drying of a invention is a compound temperature as well as mass transfer development which depends on outside variables such as temperature, dampness as well as speed of the air stream as well as inside variables which depend on parameters like angle size, water contaminant etc.

In hexagonal fish dryer there are four main parts solar space stove, drying chamber as well as rack. The clean atmosphere enter inside to the solar radiator by means of natural flow of air though the space provided at the end of it, the black colored plastic sheet absorb heat from sun light and it heat up the air which is inside the air heater, then it moves to the hexagonal drying cabinet, this movement is also natural, that is hot air always having the tendency to move upward direction.

The aluminum perforated trays with surface blackened present inside the solar drier absorbs solar heat from the incident solar radiation abundantly and dry the fishes placed on them. Doors are provided to place and remove fishes from dryer trays and also help to make clean inside of the hexagonal dryer. There is ventilation during the peak of the hexagonal freshening cavity to exhaust the wetness from inside of the assembly room.

\section{CONCLUSION}

The hexagonal solar dryer with its configuration of exposure to solar radiation is leading to increased ambient air temperature thereby resulting in increased drying rate of fishes. The fishes as are dried on the perforated aluminum plates does not get spoiled, as only the moisture is removed and they are protected from air-borne dust. As fishes are dried in an enclosure, the time spent for monitoring is drastically reduced and needs attention only while loading and unloading. Also, with the increased benefits compared to existing solar driers, the hexagonal drier provides a feasible and economical alternative.

\section{REFERENCES}

1. M. Pravin Gupta, S. Amit Das, R.C. Barai, S.C. Pusadkar, V. G. Pawar, "Design and Construction of Solar Dryer for Drying Agricultural Products", International Research Journal of Engineering and Technology, Vol. 04 No. 03, Mar. 2017, pp. 1946-1951.

2. M. Motahayyer, A. Arabhosseini, "Numerical Analysis of thermal performance of a solar dryer and validated with experimental and thermo-graphical data", Solar Energy, Vol. 193, Nov.2019, pp. 692-705

3. M. Mohanraj, P. Chandrasekar, "Perfomance of a forced convection solar drier integrated with gravel as heat storage material for chilli drying", Journal of Engineering Science and Technology, Vol. 4, No. 3, Sep.2009, pp. $305-314$.

\section{AUTHORS PROFILE}

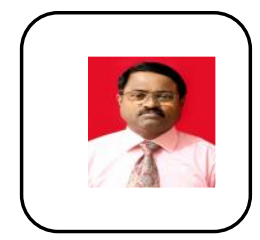

Mr. N. Lakshmi Narayanan, Associate Professor, Mechanical Engg., Aarupadai Veedu Institute of Technology Vinayaka Missions Research Foundation, Mechanical Engineer, working in the area of Renewable Energy Pursuing his Ph.D., in Mechanical Engineering at Vinayaka Missions Research Foundation in the field of Bio-energy. He is a post graduate in Thermal Sciences specialized in Energy Engineering. He has a teaching experience of around 21 years. Member in Society of Automotive Engineers, Indian Society for Technical Education, Indian Science Congress Association, Indian Institution of Production Engineers and Madras Metallurgical Society. Research areas specialized: Bio-energy, Solar Energy for Societal Applications, Alternate Fuel for Automotive Engines

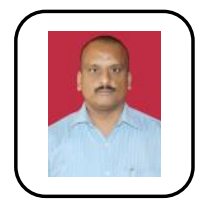

R Mahesh, Assistant Professor Grade II, Mechanica Department ,Aarupadai Veedu Institute Of Technology, Vinayaka Mission's Research Foundation, Deemed To Be University. Having 12 years of experience. Life member in ISTE and ENFUSE. 
R. Amalraj, UG Student, Dept. of Mechanical Engg, Aarupadai Veedu Institute of Technology, Vinayaka Missions Research Foundation.

Mithun. N. P, UG Student, Dept. of Mechanical Engg, Aarupadai Veedu Institute of Technology, Vinayaka Missions Research Foundation.

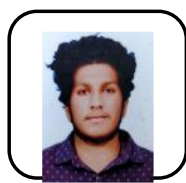

Jayakumar Nair, UG Student, Dept. of Mechanical Engg, Aarupadai Veedu Institute of Technology, Vinayaka Missions Research Foundation 